\title{
LA REVOLUCIÓN BRASILEÑA DE 1930 EN LA PRENSA URUGÜAYA
}

Raúl Federico Abadie-Aicardi*

I-INTRODUCION.

\subsection{Prensa consultada. -}

Esta comunicación se elaboró consultando las coleciones de prensa de la "Biblioteca Nacional" de Uruguay (Av. 18 de Julio 1790, Montevideo).

El relevamiento cubrió toda la prensa de la capital y una selección de la de los departamentos fronterizos con Brasil.

La nómina y caracterización del material consultado se presentan en el Anexo $I^{\circ}$.

1.2. Intención y limites de la investigación.

El relevamiento se limitó a los meses de Setiembre y Octubre 1930 - sin perjuicio de hacer algunas entradas, que se juzgaron necesarias, a meses inmediatamente anteriores - lo que indica que se buscó llegar a una idea global de la repercusión de los rumores de preparación de una revolución en Brasil (Setiembre 1930) y del conflicto armado y sus concomitancias politicas (Octubre 1930).

En el curso de estos dos meses la prensa uruguaya hace referencias al proceso brasileño anterior y se plantea algunas interrogantes sobre el futuro pero, lógicamente, el grueso del material se refiere al alzamiento armado y sus consecuencias políticas inmediatas.

\section{II - LAS NOTICIAS DE BRASIL AL SERVICIO DE FINES INTERNOS.}

II.1. Uruguay: paz e institucionalismo.

Debe recordarse que en 1930 Uruguay festejaba su centenario de existencia formalizada por la jura de su primera Constitución, en julio 1830 .

Pese a problemas politicos serios y a los reflejos internos de la crisis económica mundial, el uruguayo medio tenía la convicción de vivir en un país definitivamente estable, en el pais privilegiado de América Latina: Uruguay era "la Suiza de América" y Montevideo "la Atenas del Plata".

Es comprensible que el problema de la inestabilidad y de la revolución 
en Brasil fuese utilizado al servicio del orgulho liberal progressista y del subconciente afá de seguridade eterna (regulada por el Estado Benefactor) que por entonces dominaban al país.

Podemos imaginar la satisfación de los lectores del diario "El Nacional» del 10 octubre al informarse - por una gentil precisión en las declaraciones de Bernardino Cámara Canto, dirigente del Partido Libertador ríograndense que Uruguay había sido factor decisivo en la aceptación del principio del voto secreto por parte del también ríograndense Partido Repúblicano. Decía el señor Canto, refiriéndose a este partido: “El ejemplo de esta admirable democracia uruguaya regida por el voto secreto ha sido decisivo en el sentido de decidir a los escépticos" (1). Para "El País» del 26 octubre, la principal conclusión a extraer de los sucesos brasileños era que «En medio de América convulsionada y de Europa aquejada de un malestar que va pareciendo incurable, el Uruguay marcha en paz hacia la plenitud de las instituciones democráticas" (2).

Los acontimientos brasileños fueron también esgrimidos para servir in teresses de propaganda partidista uruguaya. Así por ejemplo, para atacar o defender el mantenimiento del Poder Ejecutivo pluripersonal e integrado por coparticipación de los dos partidos mayoritarios, establecido en la Constitución de 1918. Representante de una fracción minoritária| del Partido Colorado, enemiga de ese sistema constitucional, decía "La Mañana" del 25 octubre, queriendo señalar el peligro de la resistencia a una reforma constitucional: "estos cuatro movimientos (en Argentina, Perú, Bolivia y Brasil) fueron posibles porque en aquellas cuatro naciones habian sido conculcadas las instituciones demográticas o eran viciosas y no se admitía su perfeccionamiento" (3). Y " El Día" del 26 octubre, saliendo en defensa del Ejecutivo "colegiado", llegaba a un simplificacionismo absurdo al replicarle: "Por todos lados a través del continente americano la presidencia aparecía en crisis, siendo causante directa ya de la implantación de ominosas tiranías, ya del surgimiento de afrentosas contiendas fratricidas. (...) A los pocos dias de nuestros comentarios la Argentina se incorporaba a la lista de los pueblos anormalizados por el presidencialismo. Y antes de dos meses el Brasil pasa a ocupar un lugar en ella. Es una mala pasada que la historia les está jugando a las doctrinas riveristas" (4).

Por lo demás, la situación interna uruguaya era propensa al manejo efectista del temor a un golpe de Estado. En primer lugar, el pais se hallaba en vispera de elecciones y existía la impresión de que bien podía ganarlas esta vez el Partido Blanco, viejo adversario del Partido Colorado gobernante desde mucho tiempo atrás. En segundo lugar, em ambos partidos existían minorias vigorosas desconformes con el regimen constitucional vigente y sus consecuencias en la vida politica partidaria, insistiendo en la necessidad de cambiar de sistema. En tercer lugar, en el Partido Blanco - cuyo sector mayoritario "coparticipaba" en el Ejecutivo y en la Administración - existía una minoría acaudillada por Nepomuceno Saravia e inclinada a cambiar el regimen mediante un levantamiento armado. En cuarto lugar, dentro del Ejército - reducto del Partido Colorado - había núcleos de oficiales enemigos de la fracción mayoritaria («batllismo») de dicho partido, a la que acusaban no solamente de ejercer un "sectario" monopolio del poder dentro de diversas instituciones (entre ellas el Ejército) sino también de tener últimamente en sus filas a pequeños pero muy activos grupos de ideología marxista.

Era imaginable que el tema de un motin - monopartidista o bipartidista, 
militar o cívicomilitar, vinculado o no al cambio de regimen ocurrido en Argentina $o$ al que insinuaba en Brasil - estuviese presente en los periodicos de estos do meses que nos ocupan.

"El Día” del 14 setiembre se refería a viajes realizados por políticos opositores - colorados "riveristas" y blancos "saravistas" - para concluir que se tramaba «un plan subversivo que estallaría inmediatamente del movimento que se prepara en el Estado brasileño de Río Grande del Sur para dentro de diez o doce días" (5). En la ciudad fronteriza de Rivera, el bisemanario "Tradición Colorada" - de la fracción "sosista" del Partido Colorado - decía el 30 setiembre: «En el Brasil, desembozadamente se predica la revolución. Por esas latitudes, Flores da Cunha y João Francisco Pereira de Souza se reconcilian públicamente y se mancomunan para alzar la tea revolucionaria. Aquí, para no ser menos, el tema predilecto de la prensa es el motín. Todo el mundo habla del motin..." (6).

La vinculación de los hechos brasileños con la política uruguaya fue llevada a su punto culminante por el matutino blanco gubernista "El País", que el 22 octubre insinuaba que el Ministro de Guerra, general Manuel Dubra, habia renunciado dos días antes a raíz de una discreta reclamación diplomática de Brasil sobre "vigilancia de la frontera a fin de impedir el tráfico de armas" (7), inșinuación que no recogió nadie en el pais.

\section{II.2. Uruguay y la revolución roja.}

Como era de esperar, el vocero del Partido Cumunista utilizó con matices muy peculiares los acontecimentos de Brasil.

El diario "Justicia» del 6 octubre, luego de referirse al estallido de la revuelta armada en Brasil enderezaba hacía dónde más le interesaba y especulaba con que utambién pude tener relación el movimiento de Río Grande con las maniobras de los motineros del Uruguay quines, pretextándolo, pueden movilizar el Ejército a su antojo e ir imponiendo un fascismo "frío", de hecho, sin gran espectáculo y como forzado por las circunstancias exteriores, táctica que neutralizará a los pequeños burgueses" (8).

El 24 octubre insistía el mismo diario: «Lás noticias que llegan de Rivera son alarmantes y se vinculan a las maniobras de los motineros para pretextar la necesidad de movimientos de tropas y otras medidas que les faciliten el cuartelazo (...) La gravedad que revisten tales rumores y la intención con que se difunden se desprende de la situación crítica que atraviesa nuestra propia burguesia. Es necesàrio alertar a los trabajadores para que no se dejen sorprender con pretextos alarmistas y estar en guardia para responder sin vacilación con la huelga de masas al primer conato de motin" (9).

Naturalmente, el diario comunista buscaba vincular en forma estrecha deformando la realidad de las cosas con desenfado tipicamente stalinista la revolución brasileña con los rumores de motín uruguayo y la disposición para una huelga de masas, insistiendo en poner como centro de tal conjura subsersiva a Nepomuceno Saraiva (sobrino de Gumercindo). Decía "Justicia" el 25 octubre; "Los diarios blancos han confirmado que Nepomuceno Saraiva ofreció sus servicios de guerrillero a los 'revolucionários' brasileños. Nepomuceno, un aventurero vulgar que vende sus servicios, es hombre con vara alta dentro del Nacionalismo (el Partido Blanco). Es, además, uno de los hombres de confianza de los motineros. Con sujetos como éste es que Blancos y motine- 
ros van a 'salvar a la patria' " (10).

Debe ser puntualizado que era cierto que Nepomuceno Saraiva, continuando una tradición familiar, era caudillo muy vinculado a Río Grande del Sur y ya hemos señalado que en 1930 se declaraba, efectivamente, partidario de cambiar el regimen constitucional uruguayo mediante una insurrección armada. En el último capitulo de su libro "Memorias de Aparicio Saravia" comenta las razones de sus contactos politicos con ríograndenses en 1923 y en 1930: “Teniendo por norte la idea de buscar un apoyo eficaz para el caso de que se desconociera el triunfo del partido (Blanco) (recordemos que estaba muy cerca, como lo comprobó la jornada electoral del 8 de febrero de 1925) y estando en deuda anímica para con el Partido Republicano, que tantos servicios de importancia nos hiciera cuando la Revolución de 1904, se presentó la oportunidad de prestar mi concurso. Acompané entonces al govierno de Borges de Medeiros y combati largos meses junto a los hombres del Partido Republicano que se veian ante una revolución desatada por el Partido Maragato o Federal. Fui compañero de Flores da Cunha, de Osvaldo Aranha y de Getúlio Vargas (...) Trabé importantes relaciones y tiempos después de aquella campaña hubo de realizarse una entrevista entre los principales directivos de ambos partidos, el Nacional y el Republicano, para ajustar una alianza, entrevista que fracasó porque nuestros hombres no se hicieron presentes. (...) Si se hubiese llegado a un acurdo con los Republicanos, quizá hubiera tomado otro curso la historia de nuestra tierra. (...) En 1930 (...) Contando siempre con la la amistad de los camaradas del Brasil traté de llevar adelante la campaña anticolegialista, haciendo ver lo moroso que era obtner por medio de las disposiciones legales la reforma de la Constitución" (11).

II. 3. El anticlericalismo uruguayo.

Hacia 1930 el processo de radical laicización del Uruguay ya se habia consolidado, luego de varias décadas de combate sistemático y rencoroso contra la Iglesia. En su larga etapa de culminación y difusión, ese proceso habia sido conducido y aprovechado electoralmente por la fracción "batllista" del Partido Colorado, la cual seguía haciendo alardes despectivos o violentos.

Ante los acontecimentos de Brasil correspondió al diario vespertino de dicha fracción tocar ese punto a propósito de un mensaje del Arzobispo de Porto Alegre. Decía "El Ideal" del 13 octubre: "Nada menos que un arzobispo metropolitano, monseñor João Becker, que es el Aragone de Porto Alegre, está incorporado a la revolución ríograndense. Este monseñor ha dirigido un mensaje al clero nacional y extranjero rechazando todas las versiones que han circulado sobre los móviles del movimiento revolucionário y diciendo que éste tiene un caráter puramente político y ajeno por completo al comunismo, cuyas prácticas repele con energía (...). Claro está que hay un motivo para que este monsenhor esté de acuerdo con la revolución. El mismo confiesa que las instituciones religiosas no han sufrido nada, que el sentimiento religioso anima y fortalece a los que él llama 'nuestros soldados' y que los regimientos revolucionarios llevan capellanes militares nombrados de acuerdo con él. Siempre ha estado la iglesia del lado del más fuerte, del que tiene mayores probabilidades de vencer y cuando se ha equivocado se ha reconciliado siempre con el adversario vencedor. Monseñor Becker responde fielmente a la tradición eclesiástica” (12).

Lo más curioso es que en los dos meses desde el $1^{\circ}$ setiembre al 31 octubre 
1930 «El Ideal» brindó escasa información sobre los acontecimentos de Brasil y no dió virtualmente opinión propria sobre el tema. He aquí, pues, un caso muy representativo de cómo se presta atención a un tema y se utiliza casi exclusivamente al servicio de otras motivaciones e interesses.

\section{III - EL TIPO Y EL RITMO DE LAS NOTICIAS SOBRE BRASIL.}

\section{1. La etapa previa a la revolución.}

El largo introito que tuvo la revolución brasileña explica que hasta el viernes 3 octubre inclusive la prensa uruguaya dedicase mucha atención al tema de la situación interna de Brasil y de su probable desenlace.

Hemos estudiado el tipo de noticias classificándolas en tres categorías: a) la difusión de rumores y versiones circulantes, b) la publicación de comentarios propios del periódico (de su cuerpo de redactores y colaboradores habituales), c) la publicación de reportajes a dirigentes o simples testigos. Obviamente, en todos los casos! nos limitamos a fuentes informativas y comentarios uruguayos, excluyendo sistemáticamente del relevamiento los datos provenientes de Brasil o de terceros países.

De las tres categorías mencionadas, en esta etapa previa a la revolución predomina cuantitativamente la primera: la difusión de rumores y versiones circulantes. La casi totalidad del material capitales de los Departamentos fronterizos, sobre todo Rivera y Melo. En los primeros dias incluso se le fija fecha de estallido a la revolución. Así «El Diario» del 6 setiembre reproduce esta información desde Rivera: «Se espera de un momento a otro en Rio Grande del Sur que estalle un movimiento revolucionario. Se agrega que de no ocurrir hasta el lunes ' 8 ' ocurrirá pocos días después, por la violenta tensión de la opinión públican (13). Luego se van abandonado las profecias y toman la delantera las noticias sobre episodios locales que indican la inquietud reinante del otro lado de la frontera. Así por ejemplo, «El Día» del 9 setiembre comunica que upor la aduana de la ciudad de Rivera se despacharon días pasados numerosas caballadas, cosa que, según se dice, estaría relacionada con el probable movimiento. Y se agregaba que muchas personas conocidas de Santa Ana de Livramento habian pasado la linea, hospedándose en hoteles riverenses. Ahora nuestro corresponsal en Melo nos envía el siguiente despacho que entregamos a la publicidad sin comentarios: Melo 8. El Regimiento $8^{\circ}$ de Caballería partió para la frontera a causa de la anunciada revolución en Río Grande del Sur. Corresponsal. " (14). Y «El País» del 11 setiembre inserta esta informacion también desde Melo: "Personas llegadas de la frontera informan que en estos días se nota inusitado movimiento de personas que pasan para este lado, algunos conduciendo caballos y que se hacen eco de rumores que circulan en los parajes que habitan. Dado el estado de intransitabilidad de los caminos, que impide el tráfico de automóviles con las vecinas ciudades de Bagé y Yaguarón, no se pueden indicar noticias más concretas al respecton (15).

En cuanto a la segunda categoría (publicación de comentarios propios), puede decirse que en esta etapa tuvo muy pocas manifestaciones. Pero es preciso agregar que mientras la generalidad de la prensa - sea por escepticismo en vista de los tan reiterados anuncios sin concreción, sea por un exceso de prudencia política y preocupación de "buena vecindad" - se abstuvo to- 
talmente de dar opinión propia, los importantes periódicos "La Mañana” y "El Diario" (pertenecientes a la misma empresa editorial) hicieron algunos comentarios que, sumados a los reportajes realizados en Porto Alegre, a que hacemos referencia después, constituyen el único aporte serio durante el mes de setiembre. "El Diario" del 7 setiembre comenzaba a hacer lugar a las actividades de su enviado especial a Porto Alegre, José María Peña, regresado a Montevideo la noche anterior, con un comentario del mismo. Peña daba una versión clara y mesurada de la situación brasileña, comenzando por decir que el "programa máximo" de la Alianza Liberal era la insurrección de Río Grande del Sur, Minas Geraes y Paraíba contra el Palacio Catete, para luego dar su opinión en estos términos: "Se nos ocurre, sin embargo, que su realización resulta muy dificil y en toda su magnitud al menos puede considerarse que será imposible que se lleve a cabo (...) El espíritu público, mientras tanto, se halla sometido a una tensión expectante y casi dramática, que pude considerarse anuncio de poco agradables presagios si los acontecimentos no experimentan un vuelco completo que bien podría estar representado por un avenimiento condicional hecho sobre la base de mutuas concèsiones (...) entre los Estados "liberales" y el futuro mandatario doctor Julio Prestes" (16). Podría asignarse al mismo Peña el editorial publicado en la sección permanente de política exterior de "La Mañana" del 11 setiembre, no solamente por el estilo sino por mantener una linea similar. Luego de referirse al profundo descontento contra el gobierno central y al clima revolucionario existentes, subraya las actitudes esquivas de los dirigentes y la posibilidad de una transacción: "(Los dirigentes han dicho que solo protestarán dentro de la legalidad) y los dos grandes caudillos, el republicano Borges de Medeiros y el libertador Assis Brasil se encuentran en sus respectivas estancias, cuidando eglógicamente de sus ganados y en Minas Geraes iguales propósitos anunció su caudillo, el doctor Antonio Carlos Ribeiro de Andrada (...). Sin embargo, este pacifismo o legalismo de los dirigentes no deja de ser de media agua; Pais Filho, a rais de sus declaraciones fue más o menos alejado de la dirección del partido y muchos de los jefes ríograndenses, como lo ha manifestado recientemente el doctor Osvaldo Aranha a nuestro enviado especial, rechazan la revolución pero agregan que están convencidos de la inutilidad de las actitudes estrictamente políticas y de la necesidad de una solución de fuerza. El hecho se basaria en el deseo de no comprometer el éxito de la Alianza Liberal y la autonomía política de Rio Grande do Sul lanzándose en una aventura cuyo éxito no estuviera descontado de antemano (...) aunque se habla de revolución y se hacen conciliábulos re volucionarios, no parece que por ahora haya nada en concreto, limitándose a dejar en suspenso una temible posibilidad que, al mismo tiempo que mantiene bajo banderas al pueblo riograndense frente al Catete, aconseja a éste una politica de conciliación y de respeto" (17).

La tercera categoría (publicación de reportajes

a dirigentes o testigos) tuvo en esta etapa previa una importacia seria y, como ya lo hemos señalado, correspondió el papel principal al enviado de la empresa editora de los dos diarios antes mencionados, José María Peña. Por comentarios verbales de este distinguido periodista - muy posteriores a esta época - fue con motivo de su misión periodística de 1930 que inició su contacto con los problemas y las personalidades de Brasil. Declaraciones de Osvaldo Aranha aparecieron en "El Diario" del 9 setiembre y en "La Mañana" del 10 setiembre, con variaciones resultantes de la redacción de dos textos distintos por Peña, segura- 
mente para atender' el interés de ambos periódicos de la empresa editorial. Aranha afirma que ni él está conspirando ni es real que se esté preparando una revolución en Río Grande del Sur, explica la situación política brasileña y se declara pacifista aunque defraudado sobre la posibilidad de obtener resultados mediante los métodos legalistas seguidos hasta el momento. Peña manifiesta un aparente desconcierto: «Y no quiso explicar-nos más, reservándonos por nuestra parte el derecho de dudar - sin agravio para su sinceridad - si habíamos estado hablando con un ironista o con un estratega" (18). Decimos que nos parece un "aparente» desconcierto, porque en realidad el periodista está comprendiendo y amparando el "camouflage» del político obligado a guardar las formas. Conviene subrayar que Aranha no hace la más mínima referencia a la problemática económica de Brasil y en cambio se detiene en su papel e importancia personales. Otro reportaje de Peña, esta vez a Neves Da Fontourä, apareció en "El Diario» del 11 setiembre. Este dirigente también es esquivo sobre el tema de la eventual revolución: "puede usted informar en el Río de la Plata que en el Brasil no hay más que un solo revolucionario: es el Presidente de La República. Es él quien se ha colocado fuera de la ley violńdola a capricho" (19). En sus declaraciones incluye referencias a la situación económica de Brasil.

Otros dos reportajes enriquecieron en el curso de setiembre esta categoría. Se debieron a la preocupación por el tema por parte del diario "El Nacional» representativo de una pequeña corriente minoritaria del Partido Blanco y que poderiamos calificar como de izquierda nacional reformista. El 28 setiembre publicaba declaraciones de Alzino Marino, del Partido Republicano Riograndense, a quien el diario presentaba como ex Intendente de Bagé y llegado a Montevideo dos semanas antes. Quizá por su propia ubicación fuera de Brasil, o en nombre de una estrategia política concertada por los conspiradores, Marino habla claramente sobre el tema de la revolución, dando por evidente que ocurrirá: "en el Brasil la revolución , dando por evidentre que ocurrirá: «en el Brasil la revolución es cuestión de tiempo" (20). Y el 29 setiembre "El Nacional» reporteaba en algún lugar del Brasil a Flores da Cunha, quien también era esquivo sobre el tema de una insurrección, limitándose a sugerir: "Sí razón existío (...) para que el pueblo argentino en lucha armada terminara con el gobierno de Yrigoyen, qué no sentir en nuestro país? (21). Da Cunha prefiere extenderse sobre los problemas políticos y económicos del Brasil.

Por su posible mayor interés, reproducimos los párrafos más interesantes de los dirigentes brasileños reporteados en el Anexo II ${ }^{\circ}$.

III.2. El estallido.

Nos referimos aqui a la toma de contacto de la prensa Uruguaya con el hecho de que la revolución tanto tiempo rumureada acabada de producirse.

Es un lapso muy corto, virtualmente el fin de semana formado por el sábado 4 y el domingo 5 de ocutubre, pero de muy nutrida información cablegráfica desde las ciudades de los Departamentos fronterizos con Brasil y durante el cual aparecen diversos comentarios proprios de la prensa y algún reportaje.

Los matutinos del sábado 4 octubre tuvieron el privilegio de dar la primacia y es interesante subrayar que la casi totalidad de los cables del interior del 
pais eran originarios de Rivera. Para los ciudadanos montevideanos la revolución brasileña apareció y se mantuvo unos primeros días radicalmente asociada a los acontecimientos en Santa Anna do Livramento.

"El Día” del 4 octubre publicó una seria de cables reveladores de la muy gráfica apreciación cronológica del proceso desde la atalaya provinciana de Rivera. El primer cable dice: «Rivera 3 , hora 18 y 25 . Noticias que llegan de fuentes seguras hacen saber que han recrudecido nuevamente los rumores sobre movimientos subversivos en el Estado de Río Grande del Sur. En Don Pedrito se ha notado una gran agitación, siendo varias las personas que emigran a nuestro país con sus caballos". El segundo cable dice: "Rivera 3, hora 20 y 29, urgente. En estos momentos acaba de estallar el movimiento revolucionario en el vecino país. Se han producido fuertes tiroteos entre la Brigada estadual y el regimiento federal. Hay varios muertos y heridos. Se encuentral prisioneros el general Figueredo y octros oficiales fieles al gobierno central (...)». El quinto cable amplía: "Rivera 3, hora 22 y 09. ampliando mis anteriores telegramas debo agregar que en el movimiento revolucionário estallado a la hora 20 frente al Hotel América fue aprehendido el jefe de las fuerzas federales, general Figueredo y el jefe del $7^{\circ}$ de Cavalleria, coronel Bittencourt, que fueron sorprendidos por los oficiales revolucionarios y por tropa estadual disfrazados de campesínos, que hicieron disparos de revólver, cayendo herido un militar y dos miembros de las fuerzas revolucionárias. También resultó herido de muerte un uruguayo de apellido Aguirre, que fue la primera victima de la revolución. Al frente de este movimiento iba el coronel Chico Flores da Cunha, quein intimó la rendición de los militares federales (...). El pueblo uruguayo, aglomerado frente a la vecina ciudad, presencia los hechos" (22). Esa noche del 4 octubre "El Diario" publicaba un cable de su corresponsal en Rivera que ampliaba el horizonte de los lectores: «(...) El diputado federal Francisco Flores da Cunha, uno de los que intervinieron anoche en el arresto del coronel Bittencourt, siendo levemente herido en una pierna, ha manifestado que todo Río Grande está en pie de guerra y todo en poder de las fuerzas estaduales. Porto Alegre resistió dos horas y media, ofreciendo también resistencia Uruguayana, Alegrete y Rosario, siendo finalmente sometidos" (23).

En la categoria de los comentarios propios, ya en este breve-lapso inicial se advierte la tendencia de una parte de la prensa e rehuirlos y la de otra parte a enfocarlos, vislumbrandose en general en este caso una simpatía hacia los revolucionarios. Aparte de algunos textos de "El Nacional", interesan aqui los comentarios de "La tribuna popular" y de "El Diário". La primera, el domingo 5 octubre, luego de jactarse de haber sido de las primeras en pronosticar una revolución en Brasil y ! de ser la mejor conocedora del problema brasileño, adelantaba un pronóstico - que resultó ser bastante correcto - de la evolución del proceso bélico, señalando como factores decisivos el poderio y la unidad de Río Grande del Sur, el papel de la distancia y la necesidad de Río de Janeiro de evitar un compromiso bélico muy al sur por temor a lo que pudiese ocurrir en una retaguardia desguarnecida (24). Alguna versión oral de difícil confirmación atribuye este comentario a la pluma de Luis Alberto de Hérrera. En cuanto a "El Diario" del domingo 5 por la noche, luego de subrayar también su aporte al conocimiento de la cuestión brasileña, discurría sobre la coyuntura política y militar: "Pero el mandatario electo, antes que definirse / en favor de una transacción / prefirió callar. Se nos ocurre que el am- 
biente, a pesar de todo, habria sido propicio para intentar una conciliación. En Rio Grande, una voluntad tan poderosa como la del supremo jefe de la política local, el leader del Partido Republicano Dr. Borges de Medeiros, hasta dió a entender que no se mostraba inaccesible para la concertación, sobre determinadas bases, de un avenimiento. I A hora la clave está en la fuerza y actitud de las tropas de Río /. Las fuerzas concentradas en Río se caracterizan por su resuelta fidelidad al gobierno. Los oficiales, ligados por los princípios de disciplina y de lealtad, así como por razones de especial reconocimiento al Presidente Washington Luis, que les ha otorgado toda classe de privilegios y de mejoras, se hallarán dispuestos a extremar su resistencia» (25). El periódico tocaba asi el punto clave, pero por falta de espíritu crítico o por prudencia politica no se planteaba lo que podia ocurrir con esa fidelidad si el conflicto se prolongaba demasiado...

No se puede dejar de mencionar aquí - aunque fuese escrito la semana anterior - un comentario hecho desde Río de Janeiro por Eduardo Rodríguez Larreta para «El País» y publicado por éste el 5 octubre en que se analiza la realidad brasileña y se augura una revolución inminente (ver Anexo $\mathrm{III}^{\circ}$ ).

\section{III.3. La lucha y su desenlace en Rio.}

Durante el desarrollo de la revolución, la importancia de las três categorias que manejamos cobra caracteres diferentes.

- La información de los hechos se hace más abundante. Como la revolución se va "alejando" de su zona, los corresponsales de los Departamentos fronterizos pierden material y se van desinteresando. Paralelamente, la prensa montevideana abre espacios abundantes a cables provenientes de Brasil o de terceros paises (generalmente el tema cubre una página entera: sea alguna de las interiores dedicadas a noticias del exterior, sea la última, periodísticamente más importante, como lo hacía «El Diario", de acuerdo a su compaginación tradicional). Y sin embargo, esa mayor cantidad de información apenas si logra disimular un menor interés por un processo que se prolonga demasiado, haciendo suponer que disminuye la curiosidad de los lectores. Expresión del hecho son muchos titulares neutros o desganados, como por ejemplo el del "Diario del Plata" de 8 octubre: "A juzgar por los preparativos, la guerra civil en Brasil será cruenta y larga” (26). Luego de unos días (aproximadamente del 9 al 14) en que se observa mayor dinamismo y "El Día» titula el 14 octubre "Se acerca a un punto critico la situación en el Brasil" (27), se vuelve a un remanso y "El bien público" del 17 de octubre comunica "La situación en Brasil no ofrece mayores variantes" (28), haciendo eco "La Mañana" del 23 octubre con un aburrido "El movimiento revolucionario brasileño permanece estacionario" (29). Sorpresivamente, en la noche del 24 octubre "El Diario" da la noticia imprevista: "Esta madrugada fue derrocado el Gobierno federal del Brasil" (30). Inundada por numerosos cables, la prensa no contó con ninguno que aludiese al imponderable juego de factores que precipitaron los acontecimientos. En realidad, el análisis de los titulares constituye la única tarea interesante de este periodo, dentro de la categoría de que nos ocupamos.

- La segunda categoria, publicación de comentarios propios, toma una gran importancia, no solamente cuantitativa, sino sobre todo desde el punto de vista cualitativo. Se observa que continúa una divisió de la prensa entre quie- 
nes manifestan simpatías por la causa revolucionaria y quines prefieren mantenerse en actitud de cantelosa espera del desenlace, como fue el caso de «El Día, que recién el 25 octubre dío opinión propia sobre la cuestión brasileña, pese a habaer sido uno de los periódicos con más intensa publicación de cables al respecto (31). Los comentario refieren a diferentes aspectos. Dejamos de lado los que no son más que expresión de buenos deseos para el presente y futuro del Brasil y enunciamos la temática de mayor interés:

A) El proceso militar. - Parece excesivo pedir a una prensa no especializada comentarios profundos sobre los aspectos estratégicos de la revolución, aun cuando - por el mero hecho de la prolongación del conflito armado - bien pudo algún periódico consultar a gente entendida para desarrollar comentarios sistemáticos al respecto. El primer aporte lo habia hecho "La Tribuna Popular" el 5 octubre en términos de pronóstico inteligente y que los acontecimientos confirmaron (cf. nota $\mathrm{n}^{\circ}$ 24). "La Mañana" del 7 octubre señalaba que Río Grande del Sur "se encuentra militar y geográficamente en una cómoda posición para la insurrección" y agregaba: "En este estado de cosas, pesando probabilidades, es difícil vaticinar éxitos o fracasos en uno u otro lado. El situacionismo cuenta con grandes recursos financieros y militares, pero si las columnas revolucionarias de Río Grande y Minas Geraes consiguen entrar en comunicación y organizan una acción combinada sobre San Pablo y Río con el apoyo de las fuerzas de los distintos Estados, pueden descontarse grandes posibilidades de éxito" (32). "Diario del Plata" del 17 octubre hacía un balance objetivo, pero suavemente inclinado hacia la hipótesis de un triunfo gubernista pese a juzgar que su marina de guerra sería inoperante y que "Las medidas que sobre aprovisionamiento de víveres se están tomando en Río de Janeiro y San Pablo son un indice poco favorable para la situación probable del Gobierno federal" (33). "El País" del 20 octubre veía como elemento fundamental un estancamiento de ambos bandos debido al factor distancia, que podia comprometer peligrosamente cualquier ofensiva a fondo, diciendo que "Lo probable es pues que queden frente a frente largo tiempo, sin comprometer acción fundamental, a menos que un arreglo de ambos contendientes ponga fin a la deplorable luchan (34).

\section{B) Separatismo riograndense?. - Llevada por una curiosidad recurren-}

te y generalmente frívola - aunque apoyada en el hecho objetivo de las peculiaridades "gaúchas" y las reiteradas divergencias de Río Grande do Sul con el Gobierno central - la prensa uruguaya asoció más de una vez el tema de la revolución con el de una posible independencia riograndense. "El Día” del 8 octubre transcribia un cable de su corresponsal en Rivera en el cual se decía que en un acto político de los insurrectos algunos de ellos discuersearon "diciendo que era necesario ir a la separación de Río Grande del Sur para el bien general" (35). "El País" del 16 octubre publicada un cable de su corresponsal en Melo en el cual éste afirmaba que la población gaúcha esperaba que se crease uel Estado de Río Grande, una república próspera y floreciente» (36). Mayor trascendencia tiene el comentario que hiciera "Diario del Plata" el 18 octubre, con un tono interrogativo que indica poca convicción: / ... / Se dice que en algunas ciudades riograndenses, Rio Grande, Cachoeira y Pelotas, ha sido arriada la bandera brasileña y sustituída por la de Rio Grande del Sur. I Aunque periódicamente aflora una veta separatista en este Estado, no es demasiado vigorosa y ninguno de los dirigentes revolucionarios ha hablado de independen- 
cia actualmente / Si la revolución triunfara, muy probablemente el hecho no pasaria de los límites de un simple episodio del movimiento, porque el indiscutible ascendiente que conquistaría Río Grande del Sur en la federación bastaría para satisfacer el orgullo localista. Pero si la revolución fracasara, aceptaria Río Grande del Sur tranquilamene las consecuencias de la derrota?. Parece difícil / y por tanto, el separatismo tomaría cuerpo /. Si esto ocurriera, qué pasaria a su vez con los Estados de Santa Catalina y Paraná, plegados a Río Grande del Sur y mucho más vinculados a éste que a los demás miembros de la federación, por su posición geográfica, por sus características y por la idiosincracia de la población?" (37). El tema del separatismo, pero fundado en motivos bien distintos que los tradicionales o históricos, lo planteó también el vocero comunista: para "Justicia" del 6 octubre era la consecuencia de las rivalidades inter-imperialistas: " / .../ / el imperialismo activa sus agentes para que "independicen' los Estados del gobierno central. De Rio Grande del Sur, por ejemplo, los yanquis tienen la voluntad de hacer una colonia petrolifera, ya que sus ingenieros han llegado a sacar fotografias pueblo por pueblo y calle por calle de todo el Estado, después de haberse cerciorado de sus fuentes de petróleon (38).

C) Las fuerzas sociales en la revolución. - Sobre este importante aspecto, la prensa uruguaya es pobre, exceptuando a la de filiación marxista, a la que haremos luego referencia. Una primera excepción es el comentario de "La Mañana" del 7 octubre, el cual no va más allá de un esbozo de caracterización de la sociedad riograndense: "Río Grande ha sido el Estado díscolo y levantisco de todos las oportunidades, porque es su población donde más apasionan los problemas políticos y los deseos de renovación democrática / .. /" (39). Mayor seriedad tienen los dos comentarios de «El Nacional" (cuya ubicación ideológica hemos hecho en p. 13). El 13 octubre, luego de explicar los problemas brasileños desde la Pcia. Bernardes, se pregunta: «Si triunfa la revolución, qué perspectivas se presentarán?. Como se ve, el movimiento revolucionario es impulsado por fuerzas heterogéneas, que en épocas recientes contendieron entre sí en todos los terrenos. Si triunfa la revolución, mantendrán esas fuerzas la unidad que hoy les presta la aspiración común?. O, al contrario, se plantearán nuevos conflictos internos, retardando, quien sabe por cuanto tiempo, el retorno a la normalidad? (40). Y el 27 octubre hace un análisis de la producción y mercado del café, del comercio exterior y de las colocaciones de capital extranjero en Brasil, siguiendo cifras de Max Winckler (41) aunque no liga concretamente esos elementos con sus posibles influjos en el processo político. Podemos pasar ahora a la prensa marxista. El semanario "El Sol" (vocero del pequeño grupo socialdemócrata uruguayo) solamente se ocupó del tema brasileño el 19 octubre, de hecho para desentenderse del conflicto como desdeñable "cosa de burgueses»: «No se alcanza a percibir con toda claridad no va el verdadero origen del movimiento, su causa esencial, sino, más concretamente, sus finalidades. / Si lo provocó el resultado electoral sería / una simple revuelta intestina entre partidos burgueses, pero desorienta un tanto en la justa apreciación del espiritu del movimiento el hecho de haberse plegado a éste elementos reputados de izquierda. / El manifesto de Juárez Távóra viene a aclarar las cosas y además el alzamiento / no puede significar una reivindicación de clase por cuanto es sabido que falta en forma lamentable la conciencia y organización de clases entre el elemento obrero de aquel pais / ... / Las reivindicaciones supuestas, envueltas en las vaguedades del término 'liberal' que rubrica el actual 
movimiento, no habrán de aportar las reivindicaciones de clase del proletariado" (42). En cuanto al vocero del Partido Comunista, "Justicia», publicó numerosos informes-alegatos sobre Brasil. Ya señalamos que veía en el conflicto el resultado del choque inter-imperialista. Ahora extremaba la interpretación hasta el limite del esquematismo. El 10 octubre escribia: «Los 'revolucionarios' de la Alianza Liberal por ahora responden y hacen la politica del imperialismo norteamericano, yendo hasta la segregación de los Estados para transformarlos automáticamente en colonias yanquis. El gobierno central, en cambio, hace la política del café, cuya producción está en manos del imperialismo inglés, pero cuyo mercado en las del yanqui, contradicción que genera vacilaciones perpetuas entre un imperialismo y el otron (43). Una segunda linea de propaganda del Partido subrayaba el carácter a-popular de la revolución y su carácter de copadora de un auténtico proceso revolucionario proletario. Asi, decía "Justicia" el 6 octubre que el imperialismo hacía la "revolución preventiva" antes que la hicieran las masas miserables, las cuales se refugiaban en los bosques "alimentándose de cocos y avellanas salvajes" (sic) (44). Y el 11 octubre comentaba: "La situación es tal que los obreros abandonan rápidamente toda ilusión respecto a los bandos imperialistas en pugna y se aprestan a realizar su propia lucha. El fusil que sus enemigos - confiando en la eficacia del engaño de que les hacen víctimas - colocan en sus manos, lo volverán contra sus verdugos. En diversos puntos el combate se ha iniciado y todas las condiciones existen para que se extienda rápidamente. La revolución agraria y antiimperialista será y está siendo ya la consecuencia cierta de esta lucha armada interimperialista" (45). Para prueba de lo dicho mencionaba el alzamiento de la "Liga Revolucionaria” en Itaqui, aplastado por los rebeldes (46).

D) La rivalidad de las potencias. - Es interessante señalar que no fue privativo del vocero comunista el señalar la existencia de una rivalidad entre el imperialismo británico y el de los Estados Unidos, así como la existencia de ese factor en la situación brasileña. Que lo hicieran algunos periódicos resulta de particular interés pues indica en buena medida la repercusión de aquella rivalidad dentro mismo de Uruguay, por pugna de intereses, por afectos tradicionales o por ambas cosas a la vez. Es "La Mañana" el diario que inicia las alusiones al influjo estadounidense sobre el gobierno del Pte. Washington Luis. El 12 octubre manifiesta que con su decisión de desconocer las transacciones posteriores al 3 octubre, el gobierno revolucionario impide que ugobiernos extranjeros interesados politicamente en el mantenimiento de la tendencia actual en el Brasil presionen con todo el peso de sus dólares en el resultado de la lucha civil» (47). Y el 17 octubre es mucho más explícita al comentar: "Pero todavía queda un recurso / a favor del Gobierno federal /. Un recurso que sería preferible no ver intervenir en el conflicto interno de un pueblo latinoamericano para imponer a una parcialidad: el recurso a Estados Unidos / ... / el Catete de Río y la Casa Blanca de Washington mantienen desde muchos años atrás una especial vinculación; Brasil opera financieramente con Wall Street y económicamente depende en buena parte de la potencialidad del dólar. Esto basta para que Estados Unidos tenga interés en que en el Catete no irrumpa gente nueva y para mejor revolucionaria, gente de la cuenca del Plata / . . / La revolución triunfante sería un mal negocio para los norteamericanos o, mejor dicho, dejaria de haber en el Brasil un buen negocio. Esta gente revolucionaria, 'gaúcha' y liberal trae sus ideas especiales sobre independencia económica y 
sobre riqueza nacional" (48). Sin duda el planteo es un poco simplista, pero interesa como expresión de la poca adhesión a Estados Unidos del vocero del uriverismon, fracción minoritaria del Partido Colorado, cuyo grupo mayoritario, el "batllismo" repreentó, durante su larga gestión gubernista el traspaso de Uruguay de la órbita británica a la de Estados Unidos. En términos parecidos puede explicarse la toma de posición de "La tribuna popular", algunos de cuyos periodistas veian con mejores ojos - comparativamente - la vieja influencia británica que la ascendente de los Estados Unidos y, como sus colegas de «La Mañana" tuvieron aparentemente la esperanza de que un cambio de gobierno en Brasil fuese favorable para esa opción. Pensamos que la ponderada pero evidente simpatía de estos dos diarios hacia la revolución brasileña estuvo influida por la opción antes mencionada. El 19 octubre manifestaba "La tribuna popular" que "el gobierno del señor Washington Luis sirve mucho mejor los intereses de Estados Unidos que los intereses brasileños" (49) y el 28 octubre, apenas constituído el nuevo gobierno de Brasil, manifestaba lo que bien podríamos llamar una expresión de deseos, en esta forma: “El gobierno del Dr. Getúlio Vargas, sin embargo, representa una bien seria amenaza para los múltiples intereses yanquees en el Brasil" (50).

E) El desenlace y el nuevo gobierno. - La prensa uruguaya no acertó en la previsión del final del proceso revolucionario de octubre 1930, como surge de todo lo expresado hasta aquí. Hay, sin embargo, un comentario recogido por "El Diario" del 7 octubre que nos parece muy significativo. Se le atribuye a un pasajero del barco italiano "Conte Verde", cuyo nombre no se da y de quien se dice solamente que estando en España, antes de embarcarse, se interesó sobre el problema brasileño, reforzando su conocimiento del mismo durante las horas de escala en Río de Janeiro. Dicho pasajero anónimo, según "El Diario", expresó al periodista que el Dr. Prestes no llegaría a asumir la Presidencia, pues antes se produciría "un estado político especial", agregando que «la revolución podrá imponerse. Y ello se conseguirá cuando las guarniciones de Río procedan en el sentido que se espera. Los militares, entonces, serán los que a la postre decidirán el movimiento iniciado en forma tan alarmante / siendo de preveer que sorpresivamente se formará una junta que reformará la Constitución y llamará a nuevas elecciones / (51). Una vez que se constituyó la Junta Militar carioca, la prensa extrajo sus comentarios. Para "El Día» del 25 octubre era un hecho lamentable que parecía cerrar el paso a un caudillo civil representativo de la "ideología liberal" contraria a la conservadora (ya hemos visto que fue éste el primer comentario de "El Día» y como puede apreciarse, ahora tomaba partido sin dificultad): civilismo y liberalidad eran opuestos maniqueamente a militarismo y conservatismo, en el mejor estilo de los años dorados del Uruguay (52). "El Diario" del 25 octubre verificaba la existencia de hecho de dos gobiernos vencedores y se preguntaba hasta dónde alcanzarian sus divergencias y si seria posible una conciliación (53) y "La Mañana" se felicitaba el 26 octubre de que los militares hubiesen decidido otorgar la Presidencia a Getúlio Vargas, comentando: "lo evidente es que la orientación del nuevo gobierno habrá de ceñirsea a los rumbos que enunciara en su famoso discurso de Río de Janeiro el Presidente del Estado de Río Grande del Sur, invitado ahora a ocupar la primera magistratura de su patria. Getúlio Vargas tuvo entonces la palavra. Ahora tiene en su mano la acción realizadora" (54). 


\section{NOTAS}

- El relevamiento documental se hizo en equipo con las profesoras Lic. Milka GonzálezCamacho, Lic. Adriana Rodriguez-Buttenbender y Lic. Maria Elena Toriglia-Olascuaga.

* Doutor em História pela Universidade de Paris Professor visitante do Pós-Graduação em História PUCRS.

Professor do J.F.C. Letras de Montevidéo.

(1) “El Nacional», viernes 10 octubre 1930; p. 1, cols. 3, 4 y 5; título: "La revolución brasileña responde a factores politicos, económicos y sociales. Así nos habla el señor Bernardino Cámara Canton.

(2) "El Pais", domingo 26 octubre 1930; p. 5, cols. 4 y 5; titulo: "La paz y el orden. Puede enorgullecerse el Uruguay".

(3) "La Mañana", sábado 25 octubre 1930; p. 1, cols. 2 y 3; editorial permanente sobre politica exterior, título: "El triunfo de la revolución brasileñan.

(4) "El Dian, domingo 26 octubre 1930; p.6, cols. 2 y 3; titulo: "Una institución em crisis".

(5) "El Dian, domingo 14 setiembre 1930; p. 5, col. 6; titulo: «?Actividades motineras?" .

(6) "Tradición Colorada," martes 30 setiembre 1930; p. 3 col. 1; título: "La presión sube".

(7) "El Pais", miércoles 22 octubre 1930; p. 5, col. 3; titulo: "Otra versión sobrela renuncia del general Dubran.

(8) "Justician, lunes 6 octubre 1930; p. 6, col. 6; titulo: «?Coicidencias?. La captura de Prestes, el fascismo en el Uruguay y la sublevación en Rio Grande del Surn.

(9) "Justicia", viernes 24 octubre 1930; p. 6, col. 4; titulo: "De Brasil».

(10) "Justicia, sábado 25 octubre 1930; p. 1, col. 1; titulo: "Nepomuceno revolucionario".

(11) pp. 624 y 627 de Nepomuceno Saravia Garcia, "Memorias de Aparcio Saravia»; Montevideo $1956 ; 1^{\text {a }}$ edición, Editorial Medina; 633 páginas.

(12) "El Idealn, lunes 13 octubre 1930; p. 8, col. 3; titulo: "Un monseñor revolucionario».

(13) "El Diario", sábado 6 setiembre 1930; p. 3, col. 4; titulo: "?Revolución en Rio Grande? Rumores que circulann.

(14) "El Dian, martes 9 setiembre 1930; p. 7, col. 3; titulo: "?Revolución en Río Grande?"

(15) "El Pais", jueves 11 setiembre 1930; p. 12, cols. 1, 2 y 3; titulo: "Informaciones del Inrior. Cerro Largon.

(16) «El Diarion, domingo 7 setiembre 1930; p. 3, cols. 6 y 7; título: "La situación politica en el Brasil. Impresiones de nuestro enviado especialn.

(17) "La Mañana", jueves 11 setiembre 1930; pl 1, cols. 1 y 3 ; editorial permanente de politica exterios, titulo: «Actualidad Extrajera. La verdadera situación en Río Grande do Suln.

(18) "El Diárion, martes 9 setiembre 1930; p. 3, cols. 1 y2; título: “La situación politica en el Brasil. Habla para "El Diario" el Dr. Osvaldo Aranha, uno de los más jóvenes y prestigiosos dirigentes del Partido Republicano riograndensen. De nuestro enviado especialn.

(19) "El Diario", jueves 11 setiembre 1930; p. 1, cols. 6 y 7; titulo: "La situación politica en el Brasil. El doctor João Neves Da Fontoura habla para "El Diarion. Lo que nos dice del presente y del futuro de su pais. De nuestro enviado especialn .

(20) "El Nacional", domingo 28 setiembre 1930; p. 1, cols. 2 y 3; titulo: «En Bràsil es inminente el estallido de un movimento revolucionario. La intransigencia politica del gobierno llevaria al pais a la guerra civil. Declaraciones del señor Alzino Marinon.

(21) "El Nacional», lunes 29 setiembre 1930; p. 2, cols. 4 y 5; titulo: "Flores da Cunha, legislador - según "El Nacional» - el más grande de los politicos riograndenses, es entrevistado por un corresponsaln.

(22) "El Dian, sábado 4 octubre 1930; p. 9, cols. 6 y 7; título: «Estalló una revoución en Río Grande del Sur. El movimiento parece estar localizado en la ciudad de Santa Annan.

(23) "El Diarion, sábado 4 octubre 1930; p. 12, col. 7; título: "Las últimas noticias, todo Rio Grande está en pie de guerra (Rivera, 4, a EI Diario)" .

(24) "La tribuna popular", domingo 5 octubre 1930 ; p. 1 . cols. 5 y 6 ; título: "Al margen de la revolución brasileñan. 
(25) “El Diario", domingo 5 octubre 1930; p. 1, cols. 1 y 2; título: "El movimiento revolucionario en Brasil. Su generalización y propyecciones."

(26) "Diario del Plata. miércoles 8 octubre 1930; p. 1, cols. 2 a 7.

(27) "El Dia", martes 14 octubre 1930; p. 7, cols. 4 a 7.

(28) "El bien público", viernes 17 octubre 1930; p. 3, cols. 1,2 y 3

(29) "La Mañana", jueves 23 octubre 1930; p. 6, cols. 3 a 7.

(30) "El Diarion, viernes 24 octubre 1930; p. 12, cols. 1 a 7.

(31) "El Dian, sábado 25 octubre 1930; p. 5, cols. 1 y 2.

(32) "La Mañana", martes 7 octubre 1930; p.1. cols. 2 y 3; titulo: "Actualidad extranjera. La revolución brasileña."

(33) "Diário del Plata.", 17 octubre 1930; p. 3, cols. 1 y 2; titulo: "En el Brasil. Impresiones y perspectivas .

(34) "El Pais", lunes 20 octubre; p. 5, cols. 1 a 5; titulo: "Quien pretenda luchar en território contrario, será vencidon.

(35) "El Dian, miércoles 8 octubre 1930; p. 8, cols. 1, 2 y 3; titulo: "El movimiento revolucionario en Brasiln.

(36) "El Pais", jueves 16 octubre 1930; p. 8, cols. 5 y 6; título: "Los riograndenses creen que serán independientes. Melo 13, corresponsaln.

(37) "Diario del Plata", sábado 18 octubre 1930; p. 3, cols. 1 y 2; titulo: "Sucessos brasileñoes. El germen separatista».

(38) "Justician, lunes 6 octubre 1930; p. 6, cols. 1 a 6; titulo: "La sublevación de Rio Grande se propaga a otros Estados. La crisis hace explosiónm.

(39) "La Mañana", martes 7 octubre 1930; p. 1, cols. 2 y 3; titulo: "Actualidad extranjera. La revolución brasilen̂an.

(40) "El Nacionaln, lunes 13 octubre 1930; p. 1, cols. 3, 4 y 5; titulo: "Los sucesos que se desarrollan en Brasil constituyen la culminación de un largo proceso politicon

(41) "El Nacional", lunes 27 octubre 1930; p. 1, cols. 3,4 y 5; titulo: "La revolución en el Brasil y el capital extranjerow.

(42) "El Sol», domingo 19 octubre 1930 ; p. 1 , cols. 3 y 4 ; titulo: "El movimiento revolucionário en el Brasil».

(43) "Justician, viernes 10 octubre 1930; p. 1, cols. 1 y 2; tituo: "La revolución agraria y antiimperialista en el Brasil los obreros y campesinos contra los dos bandos imperialistas".

(44) "Justicia", lunes 6 octubre 1930; p. 6 , cols. 1 a 6 ; titulo: "La sublevación de Rio Grande se propaga a otros Estados. La crisis hace explosión".

(45) "Justician, sábado 11 octubre $1930 ;$ p. 1 , cols. 1 a 6 ; titulo: "Los obreros y campesinos brasileiros por su própia revolución. Luchas armadas por la tierra y la expulsión del imperaialismon.

(46) "Justicia", miércoles 15 octubre 1930 ; p. 6 , cols. 1 a 6 ; titulo: "La insurrección de los obreros y soldados en Itaquin. (en la col. 3 tiene una foto de Getúlio Vargas, con la indicación". "Jefe de los fascistas llamados revolucionariosn.

(49) "La tribuna popular.n. domingo 19 octubre 1930; p. 1, cols. 5 y 6; titulo: "Más allá de nuestras fronteras".

(50) "La tribuna popular.", martes 28 octubre 1930 ; p. 5, cols. 3 y 4; titulo: "La situación brasileñan.

(51) "El Diarion, martes 7 octubre 1930 ; p. 12, cols. 1 a 7 ; titulo: "Continúa desarrollándose el movimiento revolucionario en el Brasil».

(52) "El Dian, sábado 25 octubre 1930 ; p. 5, cols. 1 y 2 ; titulo: "Exterior. El motin de Rio de Janeiron.

(53) "El Diario", sábado 25 octubre 1930; p. 1, cols. 6 y 7; titulo: "El derrocamiento del gobierno en el Brasiln.

(54) "La Mañana", domingo 26 octubre 1930; p. 1, cols. 2 y 3, titulo: "Actualidad extranjera. El futuro gobierno del Brasil». 


\section{- NÓMINA E IDENTIFICACIÓN \\ DE LA PRENSA CONSULTADA.}

a) Prensa de Montevideo.

"EL DIA". - Diário, matutino, 12 páginas; portavoz de la fracción "Batllista", mayoritaria, del Partido Colorado. Muy sólida empresa comercial.

"EL IDEAL". - Diário, vespertino, 8 páginas; portavoz de la fracción "Batllista", mayoriataria, del Partido Colorado. (Misma empresa que el anterior).

"LA MAÑANA". - Diário, matutino, 12 páginas; portavoz de la fracción "Riverista", minoritária, del Partido Colorado. Sólida empresa comercial. "EL DIÁRIO". - Diário, vespertino, 12 páginas; portavoz de la fracción "Riverista", minoritária, del Partido Colorado, Misma empresa que el anterior. "EL PAĨS". - Diário, matutino, 12 páginas; portavoz de la fracción "Principista", mayoritária, del Partido Nacional (Blanco). Sólida empresa comercial.

"DIÄRIO DEL PLATA". - Diário, vespertino, 12 páginas; portavoz de la fracción "Principista», mayoritária, del Partido Nacional (Blanco). Misma empresa que el anterior.

"EL NACIONAL". - Diário, matutino, 8 páginas; portavoz de un nuevo grupo, minoritário, del Partido Nacional (Blanco). Empresa de mera intención politica.

LA TRIBUNA POPULAR". - Diário, matutino, 16 páginas; portavoz "independiente" de elementos minoritários del Partido Nacional (Blanco). Empresa de mera intención política.

"EL SOL". - Semanário (día domingo), matutino, 4 páginas; portavoz del Partido Socialista del Uruguay (socialdemocracia). Financiado por dicho partido.

"JUSTICIA". - Diário, matutino, 6 páginas; portavoz del Partido Comunista (línea Moscú). Financiado por dicho partido.

"EL BIEN PÚBLICO". - Diário, matutino, 12 páginas; portavoz de la Unión Cívica del Uruguay (democristiana). Financiado por dicho grupo.

b) Prensa del interior del pais.

"TRADICION COLORADA". - Bisemanal, 8 páginas; ciudad de Rivera, portavoz local de la fracción "Sosista", minoritária, del Partido Colorado. 
"EL RIVERISTA". - Bisemanal, 4 páginas; ciudad de Rivera; portavoz local de la fracción "Riverista", minoritária, del Partido Colorado.

"LA DEFENSA". - Bisemanal, 6 páginas; ciudad de Melo; portavoz local del Partido Colorado.

“EL NACIONALISTA». - Bisemanal, 4 páginas; ciudad de Melo; portavoz local de un grupo del Partido Nacional (Blanco). 


\section{1 - REPORTAJE A OSVALDO ARANHA, PUBLICADO EN “EL DIARIO» DE 9 SETIEMBRE 1930, p. 3, COLUMNAS 1 Y 2}

“(...) Vamos a ver, nos descerrajó, ?qué es lo que ustedes han oído de mi?, ?que soy el cabecilla de un movimiento revolucionário?, ?que estoy conspirando?. Pues bien, prosiguió, sin esperar a que redondeáramos el eufemismo con que nos proponíamos una constestación afirmativa a sus preguntas: semejantes cosas carecen de fundamento! .

"Y voy a explicarles. Hasta hace poco tiempo yo desempeñaba, por honroso encargo del Presidente doctor Getúlio Vargas, la Secretária del Interior, el Ministerio del Interior, dirían ustedes. En tal carácter tenía bajo mi mando a todos los soldados que componen la Brigada Estadual, que son más de veinte mil. Disponía además de todos los recursos inherentes al ejercicio de una buena parte del poder. Por otro lado - agregó con un dejo como de elegante e irónica jactancia, mi situación de hombre de gobierno se veía favorecida por el hecho de que yo también tengo mi leyenda más o menos heroica: dos heridas recibidas en el campo de batalha me han granjeado una cierta aureola de prestigio popular, muy indicado para erigirme en certo de una nueva revuelta armada cuando al mismo tiempo se puede disponer en forma relativamente fácil de las armas.

«De ser yo pues revolucionário (...) habría aprovechado esa oportunidad y no hubiera hecho renuncia de ella.

«(renunció a su cargo porque hoy en Brasil no se puede actuar eficazmente en política, ya que todo el poder lo ejerce el Catete). Alli se hace y deshace sin consultar a nadie y sin tener en cuenta más conveniencia que las de determinado círculo oligárquico.

"Indudablemente, no luchar contra tal situación sería una cobardía y un suicidio colectivo. Debemos luchar, pero de un modo distinto, mediante otros procedimientos que los empleados hasta a hora.

"-?Cuales?

"- No sé, los que aconsejen o impongan las circunstancias, unas circunstancias sobre las cuales, aun cuando pudiera hacerlo no desearai influir por el momento. Pero en el Brasil es urgente, imprescindible, provocar el despertar de los sentimientos hasta ahora - doloroso es decirlo - desconocidos: libertad y responsabilidad.

“(...) Y no quiso explicarmos más, reservándonos, por nuestra parte, el derecho a dudar - sin agravio para su sinceridade si habiamos estado hablando con un ironista o con un estratega (...).»

«La situación política en el Brasil.

"Habla para "El Diario» el doctor Osvaldo Aranha, uno de los más «jóvenes y prestigiosos dirigentes del Partido Republicano rio grandense. "(De nuestro enviado especial)". 
La Revolución Brasilena de ...

\section{2-REPORTAJE A OSVALDO ARANHA, PUBLICADO EN "LA MAÑANA" DE 10 SETIEMBRE 1930; P. 2, CO- LUMNAS 3 Y 4.}

«El momento politico en el Brasil. "Interesantes manifestaciones del Dr. Osvaldo Aranha.

"Una feliz circunstancia ha hecho que nuestro enviado especial a Rio Grande haya tenido ocasión de conversar extensamente con uno de los más jóvenes y prestigiosos dirigentes del Partido Republicano riograndense, el doctor Osvaldo Aranha, que hasta hace poco tiempo desempeñaba el Ministério del Interior (...).

"(Renunció a su cargo porque carece hoy de sentido actuar en política en vista de que todo se hace desde el Catete y en cuanto a la situación en Río Grande do Sul, la considera excelente por la alianza de los partidos Libertador y Republicano, los cuales) para las cuestiones de orden nacional proceden, en forma absoluta, de común acuerdo. En tales condiciones, Río Grande no podrá asumir más que una actitud: en favor de Río Grande. No hay alternativas, esa será sin dudas la única solución.

Intentamos formular una pregunta que el Dr. Aranha adivinó y prosigue: Debido a nuestros temperamento, a los riograndenses se nos hace aparecer en estos momentos en una actitud bélica. Esono puede ocultarse. Pero en el fondo de tales afirmaciones no hay más que un modo de hablar (...). La lucha, de entablarse, debiera ser de caráter nacional. Y eso no es posible. Río Grande, como todo el resto del pais, os de educación conservadora. Además, las diferencias étnicas y las distancias geográficas excluyen la posibilidad, a mi juicio, de un entendimiento colectivo entre las distintas circunscripciones politicas del Brasil. De modo que el temor a una revolución que afecte a todo el pais o a gran parte de él, debe excluirse. Y cuando usted oiga hablar, en rueda de gaúchos del próximo estallido de una revolució, recuerde que por algo se nos llama, desde Río de Janeiro especialmente, 'los españoles del sur'.

"(No cree que pronto se formen partidos nacionales en Brasil y esto se hace aun más difícil) si no se lleva a cabo la necesaria reforma electoral que reclaman nuestro progreso y hasta nuestra dignidad ciudadana. Porque el incalificable regimen electoral en vigencia en el Brasil es la causa de que ni aun en los Estados haya partidos organizados. Solo Río Grande señala una excepción en ese sentido. En San Pablo, desde hace tiempo se viene manifestando un esforzado empeño en tal sentido, pero no ha tenido ningún resultado: el Partido Democrático paulistano es solo un esbozo que ve malograda su vitalidad por la asfixia del regimen eleccionario que padecemos.

"Y al despedirnos, aquel hombre que se nos había señalado como el jefe presunto de la revolución inminente, que nos acababa de desconcertar con sus declaraciones resueltamente pacifistas, nos desconcertó una vez más diciéndonos: - Pero conste de una manera expressa que no creo en la eficacia de los medios legales. "Y no quiso explicarnos más. 


\section{REPORTAJE A JOAO NEVES DA FONTOURA, PUBLICADO EN "EL DIARIO" DE 11 SETIEMBRE 1930; p. 1, COLUM- NAS 6 Y 7.}

«La situación política en el Brasil.

"El doctor João Neves Da Fontoura habla para «El Diário".

"Lo que nos dice del presente y del futuro de su pais. (De nuestro enviado especial)n.

"(Largas declaraciones sobre la índole arbitraria del gobierno actual).

«?Y que cree usted que deben hacer los Liberales en el futuro?, interrogamos con ánimo de sondear el grado de presión revolucionária o pacifista del prestigio leader.

" - Soy de los que creen que no debe abandonarse la lucha; somos la mayor y la mejor hallan determinadas en un documento reservado que por constar de siete cláusulas ha recibido la denominación de 'eptálogo' y del que tengo el honor de ser autor, habiendo tales condiciones merecido la aprobación decidida y reiterada del jefe de nuestro partido, el Dr. Borges de Medeiros. Puedo informale que el espíritu de ese documento es el de respetar el orden jurídico tanto como el material.

"Y entonces, ?los rumores revolucionários?.

«Sonrie el Dr. Neves Da Fontoura un si es no es enigmático y como diciendo ya apareció aquello!, y nos responde:

«En cuanto a esos rumores, puede usted informar en el Río de la Plata que en el Brasil no hay más que un solo revolucionário: es el Presidente de la República. Es él quien se ha colocadora que no, el candidato de sus preferencias personales. Es por eso que nosotros no consideramos electo al Dr. Júlio Prestes, sucesor del actual mandatario y continuador de su obra. Lo reconoció el Congresso, pero no lo eligió el pueblo. Será en todo caso un Presidente "de facto" pero no 'de jure'. Y a él deberán aplicarse las solemticia su investidura, tuvo para Hermes Da Fonseca el grande e implacable Ruy Barboza.

"En primer término queríamos y queremos la reforma del regimen electoral. Luego, exijimos la adopción de medidas de apaciguamiento del espíritu público, explicablemente soliviantado de continuo; la restauración del poder legislativo, que virtualmente no existe; el afianzamiento del regimen federativo, desconocido por el gobierno de Río y, finalmente, la adopción de una politica que contribuya a sanear la Administración (...).

"(La campaña electoral) tuvo un valor tan expressivo que a pesar de las violências llevadas a cabo en contra nuestra, el gobierno federal no pudo menos que confesar que habiamos tenido 700.000 votos. Hay que conocer las gastan aquí los utileros de la máquina electoral del superior gobierno para darse cuenta que si se reconoció esa cifra fue porque la realidade la duplicó o la triplicó tal vez. Hay que tener presente que la elección se realizó únicamente alli donde no hubo más remedio; pero en muchas partes nise guardaron las formas con la organización de una parodia: en tal caso se hallan Pará, Ceará, la región toda de los sertoes del noreste, donde - por mucho que le extrañe - no hubo elecciones. 
"- ?Y quedaron sin representantes esas circunscripciones?.

«El doctor Neves nos mira con ele gesto con que Pangloss solía mirar a su discípulo y nos dice por toda respuesta: - !Cómo se ve que ustedes son ajenos al ambiente!.

"(Entre los argumentos que daba el Gobierno para que se le votase estaba el de que) él era el único que podría encontrarse en condiciones de continuar su propia obra, estaba vinculado con la grave cuestión de la estabilización de

nuestra castigada divisa monetaria (...). En este asunto, cono en el del café, no se quiso oir a los técnicos, se hizo caso omiso de los entendidos y mientras por un lado - presas de una ilusión delirante, se mantenía artificialmente la valorización del café, dándose el caso inaudito de que los hacendados pedian a Dios que mandase una helada oportunamente destructora del exceso del producto, por otro lado bastó la catástrofe del julio en Wall Street para que los banquero negassen el empréstito con que se contaba a fin de tonificar al enfermo, endeudándose de modo alarmante con el farmacéuticon.

\section{4-, REPORTAJE A FLORES DA CUNHA, PUBLICADO EN "EL NACIONAL"DE 29 SETIEMBRE 1930; p. 1, CO- LUMNAS 4 Y 5.}

«Flores Da Cunha, legislador, según «El Nacional» el "más grande de los políticos riograndenses, es entrevistado "por un corresponsal".

"La situación económica actual del Brasil. - La política nefasta del Presidente Washington Luis - comienza diciándonos el señor Flores Da Cunha ha repercutido no solamente la vida institucional del país, sino también en lo que respecta al orden económica y financiero.

"Fracasado el punto básico de su programa de estadista, que era el mantenimiento de un tipo fijo de nuestra moneda, a cuyo efecto contrató con el extranjero empréstitos fabulosos, a fin de crear una caja que la llamo de estabilización y que ya se encuentra exhausta, ningún otro recurso ensayó para salvar al país del desastre en que lo colocaba su inhabilidad para manejar los intereses públicos e igual actitud asumió respecto del problema del café, de tan desastrosas consecuencias para la economía de mi patria.

"La situación política. - Si razón existió, nos dice nuestra reporteado, para que el pueblo argentino en licha armada terminara con el gobierno de Yrigoyen, ? qué no sentir en nuestro país?.

"(...) A una pregunta nuestra sobre cual seria la actitud de los partidos opositores frente a la gestión del futuro primer mandatario del Brasil, que toma posesión de su cargo el 15 de noviembro próximo, nos contesta el señor Flores:

" - Nada ha dicho aun nuestro futuro Presidente sobre cual ha de ser su programa de gobierno. Pero si su gestión es igual a la del actual, en licha legal contra él todos los hijos del Estado y de otros Estados - como ahora, sin distinción de matices partidarios - bregando por nuestras libertades escarnecidas, por el saneamiento de nuestra política interna, por el mejoramiento de nuestra democracia y por el afianzamiento de la economía nacional». 


\section{ANEXO III}

\section{COMENTARIO SOBRE LA SITUACION EN BRASIL ENVIADO DESDE RIO DE JANEIRO POR EDUARDO RODRIGUES LARRETA Y PUBLICADO EN "EL PAÍS" DE 5 OCTUBRE}

1930; P. 5, COLUMNAS 6 Y 7.

"Desde Río de Janeiro. La gran crisis política que "atraviesa Brasil. Correspondencia del Dr. Rodríguez "Larreta." (Rio, 30 de setiembre 1930, E. R. L.)

"(...)

«? Crisis de desesperación?. - (Brasil busca afianzar su unidad y tarda en asegurarla)o El proceso tiene que resultar de una lentitud desesperante y es tal vez una crisis de esas desesperación el momento que actualmente se atraviesa.

"( No hay partidos nacionales, ni prensa nacional, porque por su propia gran extensión Brasil carece de sólida unidad).

"Sufragio popular no es democracia. - (...) Los millones de sufragios que aparecem luego en las urnas son el fruto del acuerdo de los Gobernadores de unos Estados contra los Gobernadores de otros Estados. Fueron los Gobernadores de diecisiete Estados, aceptando la candidatura Prestes, quienes le aseguraron el millón y médio de votos que lo conducen a la Presidente de la República y fueron los Gobernadores de tres Estados los que dieron a Getúlio Vargas los novecientos mil votos que lo llevan a una derrota decorosa. Los Estados se volcaban como un solo hombre a favor de uno y otro candidato. Las pequeñas minorias que aparecieron en vários constituyeron el primer sintoma, que algunos suponian augural, de una democracia orgánica futura.

«(Paraíba se negó a sostener a Prestes y su Gobernador fue asesinado). En Paraíba se ha llegado a cambiar hasta la bandera y en el centro de ella se há incrustrado como lema simbólico la frase con que el asesinado Governador Pessoa contestara la invitación para apoyar la candidatura Prestes: !Nego!.

«Río Grande, revolucionário y separatista. - Es sin embargo en Río Grande donde el problema reviste caracteres más alarmantes. Estaro rico y próspero, de población caballeresca y valiente, dotado de características típicas semejantes a las de nuestra campaña (...) hace tiempo que viene sosteniendo que no se le da en el gobierno del Brasil el sitio que le corresponde, ni se le reconocen los derechos que tiene. La derrota de Getúlio Vargas, que era tal vez la compensación ansiada, ha llevado al colmo su exasperación (...) sus caudillos no se ocultan para anunciar la revolución ni hacen un mistério que serian capaces de llegar al separatismo, proclamando la República del Sur, con Paraná y Santa Catarina.

«El movimiento no llegará a ser nacional. - ( Los inconvenientes de la gran extensión se transforman en ventaja para el mantenimiento de la estabilidad), dificil, por no decir imposible, que cualquier revolución estadual adquiera carácter nacional, saliendo fuera de los limites de sus respectivas fronteras. Cuanto más enérgia sea la reivindicación de los fueros de un Estado, más imperiosa será en el nuevo Presidente la necesidad de buscar la transacción que disuelva esta tremenda efervescência de buscar (...) Pero no creemos 
que sea destruída la estabilidad nacional, ni que la solución se busque por medio de fórmulas democráticas, para las que buena parte de Brasil no resulta aun preparado.n 


\title{
ANEXOIV
}

\author{
"EL CAUDILLO RIO GRANDENSE HONORIO LEMOS. \\ SE ANUNCIA SU FALLECIMIENTO. ERA UNO DE LOS QUE \\ PREPARABAN LA REVOLUCION. (DE NUESTRO CORRESPONSAL \\ EN RIVERA)."
}

(Publicado en «La Mañana» del jueves 2 octubre 1930 ; p. 9, columnas 4 y 5)

«Es sin duda en circunstancias especiales que viene a producirse la desaparecioń del prestigioso cabecilla, por cuanto, a estar a las versiones difundidas especialmente por sus allegados, en estos momentos se preparaba para organizar las huestes de sus parciales para la guerra civil que desde tiempo atrás se viene preparando en el vecino Estado, a pesar de que lógicamente debe considerarse que - por el momento al menos - no hay ninguna probabilidad inmediata de que sea alterado el orden.

"Se explican, sin embargo, los aprestos revolucionarios de quien, como Honório Lemos, era un profesional de la revuelta. El partido al que pertencía, que es el Libertador - vale decir, el que en Río Grande antes de la formación del frente único que ahora une a todas las tendencias representaba la oposición al gobierno central - se halla vivamente empeñado, respondiendo quizá a su tradición belicosa, en que todos los riograndense, en común acuerdo con los habitantes de Minas Geraes y Parahiba y los oposicionistas de otros Estados, se levanten en armas contra las autoriades federales. Esta es la preocupación, un poco inexplicable, de los Libertadores. Su propio leader, el talentoso e ilustrado Assis Brasil, participa al parecer de tales propósitos levantiscos.

"Ahora bien, puede asegurarse que el nexo más firme que mantiene en Río Grande el frente único está constituido por la convicción de los Libertadores de que los Republicanos, en cuyas manos está en estos momentos la autoridad estadual, están dispuestos a servir a tales designios y solo esperan el momento propício para del Brasil después, la rebelión armada.

"(Honório Lemos, uno de los mayores caudillos riograndenses, combatiente de 1923, era uno de los más decididos a alzarse).

"Según nuestras informaciones, Honório Lemos se hallaba hasta hace menos de un mes en las proximidades de Santa Ana, alojado en el establecimiento de campo de otro vehemente revolucionário, el doctor Barros Casal, el mismo a quien nuestra policia sorprendió en 1923 en las proximidades de Flo- ${ }^{a}$ rida conduciendo un camión cargado de ametrolhadoras destinadas a los rebeldes ríograndenses.

"Alli, eficazmente secundado por este jovem u decidido rebelde. Honório Lemos se preparaba para la revolución, que él y sus allegados estaban seguros no tardaria en estallarn. 


\section{ANEXO $V^{\circ}$}

\section{"LA REVOLUCION DEL BRASL Y SUS VERDADERAS CAUSAS. ASPECTOS DE LA ASPERA POLITICA RIOGRANDENSE.»}

(Publicado en «El Nacional», domingo 5 octubre 1930; p. 1, columnas 6 y 7).

"(La derrota de Vargas, considerada obra del fraude, acercó a los dos partidos riograndenses con propósitos de áctitudes heroicás).

"Ya desde la campaña presidencial, José Antônio Flores Da Cunha, lider indiscutido del bloque parlamentario 'gaúcho' y Baptista Luzardo, su adversário tenáz de ayer y sy mejor camarada de hoy, representante prestigioso a su vez del federalismo Assisista embarcado en la Alianza, proclamaban la revolución como única válvula de escape a la tensión irreprimible porque ahora atravesaba el Brasil. Según sus opiniones, reinteradas antexnutridas asambleas de los partidos unificados, un estado de degración y bancarrota como el que ofrece la república vecina, solo tolera remedios de emergência, medidas heroicas y duras como el levantamiento a mano armada."

"En eso andan actualmente. En la noche del 26 de setiembro, Flores Da Cunha, en viaje de Alegrete a Livramento, llegó a esta última con ele propósito de ultimar todos los detalles del estallido. Recibido con gran entusiasmo, el meridional abogado-caudillo descargó contra el señor Washington Luís la más temible catilinaria que se recuerda en su larga actuación tribunicia. Según el señor Flores Da Cunha el Presidente de la República es perverso, prepotente, cruel e indigno. Agregó que el pueblo riograndense debe encarar con energía y firmeza la hora sombría que vive la república, afirmando que es imperioso se sientan todos unidos y vigilantes, porque la nación atraviesa uno de esos momentos graves en los que se pone a dura prueba el patriotismo.

"Es más. Entre los aplausos delirantes de la concurrencia y dándole a sus palavras el valor de una declaración oficial emanada del núcleo dirigente de la Alianza Libertadora, Flores Da Cunha reputó fracasada toda tentativa en el sentido de evitar el choque bélico.

"Discurriendo luego la armonía de acción que debe presidir todo movimiento popular en Río Grande, olvidando rencillas y odios de antiguo arraigo, anunció que él mismo y sus hermanos ofrecían el ejemplo, pues habían llegado a reconciliarse con el coronel Juan Francisco Pereira De Souza, olvidando el pasado.

"Seis dias más tarde, en la noche del 3 de octubre (se producian) los sucesos de Livramento." 